\title{
In Praise of Phenomenology
}

\author{
Maxine Sheets-Johnstone, Courtesy Professor, Department of Philosophy, The University of \\ Oregon \\ Email:mjs@uoregon.edu
}

\section{Abstract}

A critical assessment of Merleau-Ponty's conception of phenomenology highlights singular differences between Husserl's phenomenological methodology and existential analysis, between epistemology and ontology, and between essential and individualistic perspectives. When we duly follow the rigorous phenomenological methodology described by Husserl, we are confronted with the challenge of making the familiar strange and with the challenge of languaging experience. In making the familiar strange, we do not immediately have words to describe what is present, but must let the experience of the strange resonate for some time, and even then, must return to it many times over to pinpoint its aspects, character, or quality in descriptively exacting ways. Moreover as Husserl points out, language can seduce us into thinking we know when we do not know. The methodology thus highlights the import of being true to the truths of experience, and in doing so, authenticates the basic value of a phenomenological methodology to the human sciences.

\section{Introduction}

The title of this essay is obviously related to Maurice Merleau-Ponty's essay "In Praise of Philosophy," a title that is itself the title of a book of his essays. The book was published originally in France in 1953 under the title Éloge de la Philosophie and in the United States in 1963 under the title In Praise of Philosophy. The essay was originally presented as his inaugural lecture as Chair of Philosophy at the Collège de France. In that lecture, Merleau-Ponty first discusses the works of Lavelle, Bergson, and Socrates (Lavelle and Bergson having preceded him as Chair of Philosophy), and then moves on to discuss the relationship of religion and history to philosophy, and finally, to discuss philosophy itself. He states the mission of his inaugural lecture as follows: 
Without doubt I could not do better than to examine before you the function of the philosopher, first of all as it was exercised by my predecessors, and then as it pertains to this function to consider both the past of philosophy and its present (Merleau-Ponty, 1988, p. 4).

Merleau-Ponty does not mention Husserl or the discipline of phenomenology in his discussions of past and present philosophy nor in fact in any of his discussions, facts that seem surprising in light of his mission. Merleau-Ponty had, after all, done considerable work both in terms of teaching and writing in the area of phenomenology by the time he became Chair of Philosophy in 1952. His omission of any mention of phenomenology is particularly perplexing since his appointment and the achieved fame it suggests would seem to be based on what was regarded as his innovative phenomenological vision, or more precisely, his innovative phenomenologically-influenced vision of philosophy.

Whatever the explanation, surely phenomenology warrants praise in the context of Merleau-Ponty's philosophy, for short of phenomenology, one can only wonder what path or paths Merleau-Ponty would have or could have followed short of Husserl's detailed studies of perception and cognition, of Husserl's thoughtful observations and reflective judgments of the relationship of phenomenology to science, and much more. Moreover praise of phenomenology is in fact long overdue in general, all the more so with respect to the methodology Husserl meticulously formulated. This essay aims to fill these dual lapses by following along two paths. It focuses first on Merleau-Ponty's conception, judgment, and use of phenomenology and then moves on to consider two basic values of the phenomenological method that made Husserl's phenomenological studies possible and makes all phenomenological studies possible, namely, making the familiar strange and facing the challenge of languaging experience.

\section{A Critical Look at Merleau-Ponty's Conception, Judgment, and Use of Phenomenology}

The practice of phenomenology is edifying. In good measure, this is because the practice requires practicing a method. To acquire knowledge of the method requires reading Husserlian texts and thereby understanding not just the procedural sequence of the practice, but the challenges of the practice and the fruits of the practice. Consider, for example, certain descriptive terms found in phenomenological texts: "the zero point of orientation," "the comet's tail of nature," "intertwining," and "I can," descriptive terms that Husserl uses in the course of his analyses as a result of the methodological practice and that pinpoint various living realities: the ever-present hereness and nowness of the body in relation to the world in the first instance (Husserl, 1989, pp. 61, 135; Husserl, 2001, pp. 584-585); the relationship of free acts of the Ego to the Ego's rich history of experience in the second instance (Husserl, 1989, p. 350); the "double-sided unity" of sensing and willing, of sensuous and meaning, and so on, in the third instance (e.g., Husserl, 1977, pp. 151-153 [see also “intertwining," e.g., pp. 6, 26], Husserl, 1989, pp. 297-98, 352); and the faculty of spontaneous and freely-willed movement in the fourth instance (Husserl, 1980, p. 107; 1989, pp. 159-160, 266). It is notable that Merleau-Ponty appropriates each of these descriptive terms either without referencing Husserl or with a less than full elucidation of them and in fact redefines them in the process. He uses "the comet's tail of nature," for example, in his attempt to elucidate "the phenomenon of movement" (Merleau- 
Ponty, 1962, p. 275). He uses the concept of intertwining, for example, not only when he writes of the chiasm and reversibility (Merleau-Ponty, 1968, pp. 130-155), but when he writes of the "interfusion between sexuality and existence" (Merleau-Ponty, 1962, p. 169). ${ }^{1}$ He uses the concept of "the zero point of orientation" as a "system of possible actions," those of a "virtual body with its phenomenal 'place' defined by its task and situation" (Merleau-Ponty, 1962, p. 250). ${ }^{2}$ He uses "I can" as the distinguishing feature of consciousness, oddly enough crediting such a usage to Husserl, i.e., "This term is the usual one in Husserl's unpublished writings" (Merleau-Ponty, 1962, p. 137).

Merleau-Ponty's usage of Husserl's descriptive terms, terms that are the result of Husserl's practice of his phenomenological methodology and analyses, is notable precisely in light of Merleau-Ponty's disclaimer regarding phenomenology methodology and his eschewing of the practice of phenomenology in favor of "existential analysis" (Merleau-Ponty, 1962, p. 136). Phenomenology becomes in Merleau-Ponty's account simply individualistic_- "We shall find in ourselves, and nowhere else, the unity and true meaning of phenomenology" (MerleauPonty, 1962, p. viii) - even though at the same time, according to Merleau-Ponty, "Phenomenology is accessible only through a phenomenological method" (Merleau-Ponty, 1962, p. viii). We are thus left with a veritable puzzle as to the value of Husserl's phenomenology and the value of the phenomenological method: "phenomenology" is put forth as a solely personal expedition and exposition that nevertheless owe their existence to $a$ phenomenological method, an apparent species of one sort or another of the method Husserl detailed, presumably a species such as "existential analysis."

A further critical point warrants attention with respect to phenomenological methodology, namely, a concern with Merleau-Ponty's reproving comments about the phenomenological reduction that is integral to the methodological practice of phenomenology. When Merleau-Ponty's claims, "The most important lesson which the reduction teaches us is the impossibility of a complete reduction," he rests his claim essentially on his claim that body and world are already there (Merleau-Ponty, 1962, pp. xiv, 198). His claims, however, are wide of the mark. The phenomenological reduction is in the service of constitution, that is, in the service of bringing to light how meaning and value come to be, how, through active and passive syntheses, through horizons of meaning and sedimentations, and so on, we come to make sense of the world. The existence of the world and the existence of body are not in question in the practice of phenomenology; both are present in their full reality. What phenomenological methodology provides is a pathway to understanding how that reality is constituted. Husserl in fact terms this genetic phenomenology, this historical mapping, a "phenomenological-kinetic method" (Husserl, 1980, pp. 1, 117-118): it moves through the layers of meaning that constitute sense-making.

Husserl's writings indeed meticulously counter Merleau-Ponty's “important lesson.” In his elucidations of the phenomenological reduction that opens a transcendental field, Husserl painstakingly points out and in exacting fashion,

\footnotetext{
${ }^{1}$ As noted elsewhere "We see across the whole of Merleau-Ponty's developing existential analyses the conceptual bond between intertwining and ambiguity that is everywhere descriptive of life" (Sheets-Johnstone, forthcoming 2017).

${ }^{2}$ A clearly adultist claim since infants are clearly engaged in learning their bodies and learning to move themselves prior to being engaged in any task, and hence to being a body in face of its tasks!
} 
Within my field of transcendental phenomena [i.e., within the "transcendentalphenomenological reduction ... by means of which the natural attitude, the attitude of inner psychology, is transformed and becomes a transcendental attitude"] I no longer have theoretical validity as a human Ego; I am no longer a real Object within the world which I accept as existing, but instead I am posited exclusively as subject for this world. And this world is itself posited precisely as I am conscious of it in some fashion or other, as appearing to me in a certain way or as believed, predicatively judged, valued, etc. (Husserl, 1989, pp. 413) ${ }^{3}$

By specifying in exacting terms the nature of the ongoing ontological reality and relationship of subject-world in the reduction, he in fact shows how reciprocal understandings may be formed between phenomenological psychology and transcendental phenomenology, that is, between the "natural" and the "transcendental" and what he views more broadly as between empirical science and transcendental science.

In this context it is instructive to point out that what Merleau-Ponty considers an individual labor - i.e., "We shall find in ourselves, and nowhere else, the unity and true meaning of phenomenology."-- is not in truth an investigative - or interrogative-free-for-all, so to speak. Individual explorations in phenomenology follow along formal methodological lines, precisely as in science. What Husserl formulated methodologically is in fact an individual procedure that involves steps that are specifically individual steps, yet steps that are related to individual steps taken by others. Indeed, what Husserl himself writes in an essay titled, "Denial of Scientific Philosophy," an essay that Merleau-Ponty utilizes and indeed shapes to his own end (MerleauPonty, 1988; see particularly pp. 3-67, 167-191), is instructive. Husserl states, "I know, of course, what I am striving for under the title of philosophy, as the goal and field of my work. And yet I do not know. What autonomous thinker has ever been satisfied with this, his 'knowledge'?" (Husserl, 1970, p. 394).

Husserl's point is precisely that there is a "historical tradition" (Husserl, 1970, p. 394) that "his own aim [exists] in relation to others" (Husserl, 1970, p. 395). In short, Husserl affirms that "Every philosopher 'takes something from the history' of past philosophers . . . and makes more or less use of the possibility of entering into a personal exchange of ideas with still living fellow philosophers" (Husserl, 1970, p. 392). His forthright recognition that some might find the phenomenological reduction outlandish is notable in light of his recognition of the play of history, most specifically with respect to what Merleau-Ponty regards as the impossibility of a complete phenomenological reduction. Husserl addresses potential critics such as MerleauPonty directly. He writes, "In fact here reside the greatest stumbling blocks on the path to understanding, for one will no doubt feel it is asking much too much that a mere 'nuance', arising out of a simple change in attitude, should have such a great significance and indeed be decisive for all genuine philosophy" (Husserl, 1989, p. 414). In lucid fashion, he proceeds immediately to add:

\footnotetext{
${ }^{3}$ The transcendental has to do precisely with constitution, with meaning-giving, hence with exacting analyses that go beyond whatever is sensuously present — be it a house, a chair, a tree, or whatever - and answer to the question of how the sensuously present comes to be known, judged, valued, and so on, in the first place. Hence, as we shall see specifically within Section II, the first step in the practice of phenomenology requires that what is transcendent is bracketed such that the familiar becomes strange.
} 
The totally unique significance of this 'nuance' can become evident only by means of a radical self-understanding on the part of the philosopher with regard to what he properly wants to attain under the title of philosophy and with regard to the extent to which he must want something different in principle from 'positive' science, thus something else than domination, in theory, of the pregiven world of experience. (Husserl, 1989, p. 414)

In short, the individual labor that goes into the practice of phenomenology is personal, but the knowledge that emanates from it is not merely personal, and this because, if carried out assiduously, the practice of phenomenology eventuates in foundational knowledge, knowledge that gets to the bottom of the essential nature of a phenomenon or how a phenomenon comes to have the meaning and value it has. In short, in virtue of the phenomenological method and through the practice of the phenomenological method, one opens up "the pregiven world of experience" and elucidates its manifold aspects and history for all.

A decisively important value of phenomenology should be mentioned in the context of opening "the pregiven world of experience" for all, a value that commonly goes overlooked. What many a phenomenologist appears to forget is that phenomenological analyses and conclusions are open to verification, precisely by those who follow through methodologically, a distinctively formal procedure that some may eschew on behalf of their own investigations. Of note in this regard is the fact that Merleau-Ponty mixes his criticisms of Sartre's ontology of the for-itself and in-itself with his criticisms of Husserl's phenomenological analyses of intersubjectivity, thus jumbling and falsely assailing Husserl's phenomenology of an intersubjective world and the phenomenological methodology on which it is based (MerleauPonty, 1988, pp. 174-175, 176). He furthermore erroneously aligns Husserl's phenomenology with that of Heidegger, equating Husserl's phenomenology with an effort "to recover through an absolutely new way of thinking the experience which underlies metaphysics" (1988, p.177). He thereby affirms a revolutionary ontological philosophy: "[P]hilosophy takes its start . . . in a 'there exists', in an 'opening' toward 'something', toward 'that which is not nothing. It is this preobjective Being, between the inert essence or quidditas and the individual localized at a point of space-time, that is the proper theme of philosophy" (1988, p. 178). Husserl's emphatic affirmation that "ontology is not phenomenology" (Husserl, 1980, p. 117; italics in original) is all the more of moment in light of both Merleau-Ponty's characterization of Husserl's phenomenology and Merleau-Ponty's avowal of a phenomenology anchored in an ontological philosophy.

The phenomenological method that Husserl formulated is indeed an epistemological, not an ontological, undertaking. That it is so makes the openness of phenomenological analyses to verification all the more meaningful. On the one hand, what is put forth in any analysis may be amended, extended, questioned, elaborated, and so on. On the other hand, the openness of phenomenological analyses to verification is similar to verification in empirical sciences. Given his deep interest in science, it is indeed odd if not incomprehensible that Merleau-Ponty would ignore the possibility of explicitly verifying the many concepts he picks up from Husserl's phenomenological analyses. What appears to stand in the way of explicit verification is the promotion of a different kind of practice: Merleau-Ponty as well as Derrida, Heidegger, and other phenomenologists carry out studies that are individualistic and that implicitly affirm as Merleau-Ponty affirms, "We shall find in ourselves, and nowhere else, the unity and true meaning of phenomenology" (Merleau-Ponty, 1962, p. viii). 


\section{Epistemological Challenges and Fruits of Phenomenological Methodology}

Husserl's phenomenological methodology asks us first to make the familiar strange. In effect, through the procedure of bracketing, one defuses reactive or reaction-type responses and lets the sensuous reality of what is present sink in - deeply, into one's bones. The result for the phenomenologist is to greet the phenomenon as if for the first time in order retrospectively to understand how what was once strange came to be familiar, that is, how it came to be meaningful in the ways it now is. As noted elsewhere, "Phenomenological analyses and descriptions . . . take us back to origins; we come to understand how, in Husserl's words, things come to have the meaning and value they do," (Sheets-Johnstone, 2002, p. 170). In short, phenomenological analyses disclose processes of sense-making at the core of experience. They disclose how we come to constitute the world in the course of our experiences of it, and constitute it in finely tuned conjunction with being an "animate organism" (Husserl, 1989, 1980, 1973a), i.e., with being an animate form of life, or in short, with being a body (Sheets-Johnstone, 1990, 1994, 1999/exp. $2^{\text {nd }}$ ed. 2011). Our bodies are indeed semantic templates. Hence it is not surprising that fundamental human concepts are corporeal concepts, and that concepts in the nonhuman animal world are equally corporeal concepts (Sheets-Johnstone, 1990).

A further aspect of making the familiar strange warrants attention. As detailed elsewhere (Sheets-Johnstone, 2014a, pp. 97-98),

The formation of habits proceeds in just the opposite manner of the practice of phenomenology. In doing phenomenology, that is, in following its methodology, we not only make the familiar strange, but do so in part by disenfranchising our habits, i.e., by bracketing, by 'renounc[ing] all erudition, in a lower or higher sense' (Husserl, 1989, p. 96). Across the spectrum of human cultures, that is, in the most basic ontological sense that includes every human, habits are indeed a matter of having made the strange familiar. That familiarity becomes ingrained in what Husserl terms the "psychophysical unity" (Husserl, 1973a, p. 97) of animate organisms and their ways of living in the world. In more precise terms, habits develop by bringing what was out of reach and/or beyond understanding effectively and efficiently into the realm of the familiar and into what are basically synergies of meaningful movement that run off by themselves. Habits are indeed grounded from the beginning in movement, that is, in the primal animation of animate organisms that gives rise to sensings and sense-makings that evolve into synergies of meaningful movement and habits of mind. It is hardly any wonder, then, that foundational understandings of habit, its origin, nature, and genesis, are rooted in a 'regressive inquiry' (Husserl, 1970, p. 354) into ontogenetic life, or what Fink terms a 'constructive phenomenology' (Fink, 1995, p. 63).

The phenomenological reduction is made possible by "bracketing." Husserl spells out this relationship when he writes, "[E]verything transcendent that is involved must be bracketed, or be assigned the index of indifference, of epistemological nullity, an index which indicates: the existence of all these transcendencies, whether I believe in them or not, is not here my concern; this is not the place to make judgments about them; they are entirely irrelevant" (Husserl, 1973b, p. 31). Making the familiar strange is thus of quintessential epistemological value. To take the phenomenon of movement, for example, we put aside the notion that movement is a "change of 
position" as dictionaries tell us; we put aside the notion that movement is a force in time and space as objective measurements tell us; we confront the entanglement of movement with objects in motion and put aside the latter, thus leaving ourselves with the phenomenon of movement pure and simple, recognizing in the course of our analysis how aspects of objects in motion are or can be inherent dimensions of movement. ${ }^{4}$

One might be tempted to say that Merleau-Ponty was making the familiar strange by his appeal to pathology, in particular by focusing on the patient named Schneider, but that would be to make the familiar strange from a distance. The focus of attention was not first-person experience, not a phenomenological investigation, but what one might rightly term a hermeneutical exercise, that is, an interpretive venture into the experience of another, another who, by the way, with respect to Merleau-Ponty's "existential analysis," was not observed directly as in philosopher Ernest Cassirer's personal studies of Schneider (Cassirer, 1957, p. 239), but was interpreted behaviorally on the basis of the writings of Kurt Goldstein about Schneider. ${ }^{5}$ In sum, making the familiar strange is a mandatory phenomenological first step that wipes the theoretical-ideational slate clean and in doing so makes way for an unprejudiced analysis, and, in turn, enlightened understandings of the phenomenon in question.

Making the familiar strange is edifying. One learns not just that one has taken this or that for granted or that this or that definition or descriptive characterization is questionable or downright deflective; one learns how much one does not know about the phenomenon in question. It is precisely in this context that one is thrown up against the challenge of languaging experience. One may not have immediate words to describe what is there, sensuously present in experience. There are thus terminological issues that one may contend with, terminological issues emanating from ways in which a phenomenon has been commonly labeled. Consider, for example, the labels "body image" and "body schema." The former is defined as "perceptions . . . pertaining to one's own body," more specifically, "perceptions" that are the first "intentional element" of "embodied experience" (Gallagher, 2000, pp. 4, 2, respectively). The latter is defined as "a system of processes that constantly regulate posture and movement ... [and] that function without reflective awareness or the necessity of perceptual monitoring" (2000, p. 4). A number of problems attach to these labels, foremost among them the fact that an image is not a

${ }^{4}$ Linear and areal qualities of movement have both a design and pattern aspect. The design aspect describes the linear and areal qualities of a moving body; the pattern aspect describes the linear and areal qualities of movement. Consider, for example, a run across a field: the linear design of the body is changing as legs are describing a circular pattern, arms are moving forward and back, and the body as a whole is going up and down. The linear design of a falling leaf, in contrast, does not change as the linear pattern described by the falling leaf does change: the leaf wafts to one side and then the other; it does not commonly go down in a straight line in one fell swoop.

${ }^{5}$ While Merleau-Ponty read the writings of Gelb and Goldstein, Cassirer visited the Frankfurt Neurological Institute where Gelb and Goldstein conducted their research. He observed patients at the Institute and even had "frequent conversations" with a patient (unnamed, but quite likely Schneider, a patient whose spatial sense of his own body, including its orientation, was severely damaged, and whose capacities and lack thereof were at the time taken to be basic to phenomenological understandings of the body and space) (Cassirer, 1957, p. 239). It is not surprising, then, that Goldstein cites Cassirer substantively in his own writings (Goldstein, 1939, 1940). 
perception, much less a proper description of the felt qualitative dynamics of affect or the felt qualitative dynamics of bodily movement, the latter dynamics having been termed "kinesthetic melodies" by neuropsychiatrist Aleksandr Luria (Luria, 1966, 1973); and the fact that a schema tells us nothing about coordination dynamics; dynamics that J. A. Scott Kelso, founder and for 20 years Director of the Center for Brain and Behavioral Studies at Florida Atlantic University, has painstakingly researched and critically contrasted to "explanatory mechanisms" postulated by neuroscientists, mechanisms such as "switches" or "schema" or "traces" (Kelso, 1995, p. 57). In short, commonly used terms may be not only commonly deflective of a proper description of a phenomenon but in fact distract from being true to the truths of experience.

With respect to being true to the truths of experience, commonly used terms may raise conceptual issues as well. For example, philosopher Shaun Gallagher specifies two intentional elements of body image based on the first intentional element identified as perception. These further intentional elements are specified as "the subject's conceptual understanding . . . of the body in general; and the subject's emotional attitude toward his/her own body" (Gallagher, 2000, pp. 4-5). Surely the question one may ask is how the term 'body image' can possibly stand for, much less encompass or describe, not only perceptual, but conceptual and emotional aspects of a subject's first-person experience of his/her own body. Surely the most basic aspect of being a body, a living body, is incontrovertibly its animation: "in the beginning and straight through to the end, the quintessential aspect of one's body - and in fact any living body - is movement" (Sheets-Johnstone, 2005, p. 218; see also Sheets-Johnstone, 2009, 2014b). ${ }^{6}$ Moreover the quintessential conceptual and emotional aspect of a subject's experience of his/her body is not simply the fact that it moves, but that it is moved to move, movedboth cognitively and affectively. Indeed, we judge that a body is alive in virtue of a freely moving body. Further still, when we duly widen our perspective on life, we recognize the fact that we come into the world moving; we are precisely not stillborn. What this ontogenetic point of view furthermore demonstrates to us is that movement forms the I that moves before the I that moves forms movement (Sheets-Johnstone, 1999/exp. $2^{\text {nd }}$ ed. 2011: e.g., pp. 137-138, 265-266/e.g., pp. 119, 201, 459). Indeed, it straightaway demonstrates to us that movement is our mother tongue (1999, pp. $226,229,258 /$ exp. $2^{\text {nd }}$ ed. 2011 , pp. $195-196,334,514$, pp. $226,229,258 /$ e.g., pp. 195-196, 334, $514)$.

In sum, when we make the familiar strange, we set ourselves up to meet the challenge of starting from scratch and are in turn thrown up against the challenge of languaging experience. We may not have immediate words to describe the phenomenon in question. We may not know what to term this or that apparentness or aspect. We may need to let the strange resonate for a considerable amount of time. In the course of that time, we may discover that the form of the strange matters. We may discover that its affective qualities matter. In the end, we realize that its description matters and that indeed, more generally, that descriptive foundations matter. Descriptive foundations are, after all, the bedrock of science and of literary studies as well as phenomenology (Sheets-Johnstone, 2002). Descriptive foundations surpass naming. They approximate as closely as possible the nature and character of a phenomenon. Darwin understood

\footnotetext{
${ }^{6}$ Animation is actually theoretically of a piece with the biological concept of "responsivity:" "Plant seedlings bend toward light; meal-worms congregate in dampness; cats pounce on small moving objects; even certain bacteria move toward or away from certain chemicals... [T]he capacity to respond is a fundamental and almost universal characteristic of life" (Curtis, 1975, p. 28).
} 
the value of descriptive foundations in his finely detailed studies of all forms of animate life, from invertebrates to vertebrates, of the effect of morphology on the living of life, and of the interconnected evolutionary nature of animate life. When we read the novels of Dostoyevsky or James Joyce or William Faulkner, we are rapt in the lives of others who, in virtue of a descriptive narrative, are alive to us.

When we engage in the actual practice of phenomenology and meet the challenge of languaging experience, what we elucidate are living dimensions of a subject-world relationship. When we apply ourselves to an investigation of the relationship of movement and emotion, for example, we come to appreciate not only the basic dynamic congruity that obtains between movement and emotion, but the fact that that congruity is the very basis of our being able to feign and restrain an emotion. If that natural dynamic congruency of movement and emotions did not exist, we would hardly be unable to feign a smile or restrain an impulsion to strike someone. The natural dynamic congruity of emotion and movement basically moves us to move in the ways we do and to move efficiently and effectively in the world. ${ }^{7}$

\section{Concluding Thoughts}

In her communications to IHSR members prior to the 2016 conference, Rebecca Lloyd asked:

What are the affects and effects of an enhanced phenomenological sensitivity? What senses, feelings, emotions and moods of self-affirmation and responsiveness to others sustain us in our daily lives? To what extent might the descriptive, invocative, provocative language of phenomenology infuse the human sciences and engender a language for speaking directly of life?

I did not state Lloyd's questions or even allude to them in the beginning of this essay because to have done so would have likely made it seem as if this essay was an attempt to answer them. Presenting the topic of praise for phenomenology along with a discussion of reasoned and justifiable evidence for claims on behalf of the topic afforded a broader, more open and straightforward presentation and consideration of the topic. In fact the foregoing essay was not written to provide conclusive answers to any questions. The essay is an attempt to open a field of inquiry, not to close it, and certainly not to parade as conclusive. In effect, the concluding thoughts that follow are concluding only in the sense of bringing this essay to a close in a way that heightens the value of praising phenomenology, in particular, of bringing to light basic values of the phenomenological method that make bona fide phenomenology analyses of moment to the human sciences. As detailed above, when one makes the familiar strange, one is thrown up against the challenge of languaging experience. One commonly does not immediately have words to describe it, but must let the experience of the strange resonate for some time, and even then, must return to it many times over to pinpoint its aspects, character, or quality in

\footnotetext{
${ }^{7}$ For more on the dynamic congruity of emotion and movement, see Sheets-Johnstone (1999/2009).
} 
descriptively exacting ways. When we are at a loss to name something, the typically unnoticed challenge of languaging experience is directly experienced and even heightened. Two observations made by Husserl in the course of his analyses are instructive in this regard. They explicitly highlight the challenge in distinctively different ways.

In his analysis of internal time consciousness, specifically, in his attempt to describe the temporality of consciousness, Husserl comes to an impasse. It will not do to specify the inherently temporal nature of consciousness - what he designates as "absolute subjectivity"-- as a series of "nows," even an interconnected series of "nows" as one would describe an immanent object. He in fact asks himself, "But is not the flux a succession? Does it not, therefore, have a now, an actual phase, and a continuity of pasts of which we are conscious in retentions?" (Husserl, 1964, p. 100). He answers,

We can only say that this flux is something which we name in conformity with what is constituted, but it is nothing temporally 'Objective'. It is absolute subjectivity and has the absolute properties of something to be denoted metaphorically as 'flux', as a point of actuality, primal source-point, that from which springs the 'now', and so on. In the lived experience of actuality, we have the primal source-point and a continuity of moments of reverberation.

His final comment is striking: "For all this," he writes, "names are lacking" (1964, p. 100)

Dynamic phenomena are indeed a challenge to name, for what is dynamic does not stay in place. While one might say that one is experiencing a something rather than nothing, that something exceeds solid specification. What is dynamic is, in other words, not like a chair or even like a tree that, its growth and limb and leaf movement notwithstanding, has a spatially set reality that is unchanging. It does not move, hence presents itself as atemporal. Dynamic phenomena clearly present a challenge. One might take this challenge into account in considering physicists' seeming predilection for particles over waves. Moreover one might well suggest that the zeal with which present-day neuroscience attempts to locate where this or that is happening in the brain is a further example of a predilection for what is solid over what is dynamic, in this instance, over the living dynamics of the hundred billion neurons in the human brain, not to mention the living dynamics of the whole-body nervous system that includes the brain. In sum, while names may well be lacking, the recognition of dynamics, of phenomena that exceed placement, is a vital first step toward understanding vital dimensions of life, consciousness and movement being foremost among these dimensions, perhaps even vital first steps toward understandings of life itself.

The second observation concerning language is found in the course of Husserl's analysis of the origin of geometry. Early on in the analysis, he notes that language is part of civilization: "Clearly it is only through language and its far-reaching documentations, as possible communications, that the horizon of civilization can be an open and endless one, as it always is for men" (Husserl, 1970, p. 358). But he goes on to consider meaning and confronts the fact that meanings can arise passively and over time: "Passivity in general is the realm of things that are bound together and melt into one another associatively, where all meaning that arises is put together passively" (1970, p. 361). At a later point he gives an example of this passivity. "Consider, for example, the way in which we understand, when superficially reading the newspaper, and simply receive the 'news'; here there is a passive taking-over of ontic validity 
such that what is read straightway becomes our opinion" (1970, p. 364). But he specifically contests this passive taking-over when it is a question of explicating meaning:

"But it is something special," he writes, "to have the intention to explicate, to engage in the activity which articulates what has been read (or an interesting sentence from it), extracting one by one, in separation from what has been vaguely passively received as a unity, the elements of meaning, thus bringing the total validity to active performance in a new way on the basis of individual validities." (1970, p. 364)

This labor of explicating is, as Husserl suggests, a matter of bringing to self-evidence. Earlier, however, he has pointed out that the attempt to reactivate meaning may be unsuccessful, that it "comes to nothing" because reactivation of the whole is not possible: While individual units or elements of meaning may be reactivated, the unified whole of meaning cannot. As Husserl puts it, "ontic validity is destroyed through the original consciousness of nullity" (1970, pp. 361-362). It is in this context that he makes a strikingly perspicuous observation about language. He observes,

It is easy to see that even in [ordinary] human life, and first of all in every individual life from childhood up to maturity, the originally intuitive life which creates its originally self-evident structures through activities on the basis of sense-experience very quickly and in increasing measure falls victim to the seduction of language. Greater and greater segments of this life lapse into a kind of talking and reading that is dominated purely by association; and often enough, in respect to the validities arrived at in this way, it is disappointed by subsequent experience. (1970, p. 362; italics in original)

Husserl's concern is precisely with science, specifically with, one might say, the easy acceptance and even acquisition of "science talk." Though Husserl does not give an example, we might readily give one and in fact more than one: not only "the big bang," for example, but embodiments of all kinds, as in embodied language, embodied experience, embodied subjectivity, and even embodied movement. What Husserl does point out, however, is worth noting. He states, "In view of the unavoidable sedimentation of mental products in the form of persisting linguistic acquisitions, which can be taken up again at first merely passively and be taken over by anyone else, such constructions remain a constant danger" (1970). Earlier remarks in the present essay concerning body image and body schema are of course also a case in point, but so too is the use of language in phenomenology itself, as in the word "prereflective," the usage of which is taken for granted i.e., it is commonly unelucidated as to what precisely it stands for, much less describes). In short, we humans can indeed be seduced by language, seduced to the point of thinking we are saying something, writing something, or understanding something when in fact the real-life, real-time dimensions of the phenomenon elude us.

\section{References}

Cassirer, E. (1957). The Philosophy of Symbolic Forms, Vol. 3: The Phenomenology of Knowledge, trans. Ralph Manheim. New Have, CN: Yale University Press.

Curtis, H. (1975). Biology, $2^{\text {nd }}$ ed. New York: worth Publishers. 
Fink, E. (1995). Sixth Cartesian Meditation. (R. Bruzina, Trans.). Bloomington, IN: Indiana University Press. (Original work published in 1988 by Kluwer Academic)

Gallagher, S. (2000). Phenomenological and Experimental Research on Embodied Experience. Paper presented at Atelier Phénomenologie et Cognition, et Cognition Research Group, CREA, Paris, pp 1-29, France..

Goldstein, K. (1939). The Organism. New York: American Book Company.

Goldstein, K. (1940). Human Nature in the Light of Psychopathology. Cambridge: Harvard University Press.

Husserl, E. (1973a). Cartesian Meditations. (D. Cairns, Trans.). The Hague: Martinus Nijhoff. (Original work published 1950.)

Husserl, E. (1973b). The Idea of Phenomenology. (W. P. Alston \& G. Nakhnikian, Trans.). The Hague: Martinus Nijhoff. (Original work published 1907.)

Husserl, E. (1977). Phenomenological Psychology. (J. Scanlon, Trans.). The Hague: Martinus Nijhoff. (Original work published 1962; revised with corrections 1968.)

Husserl, E. (1980). Ideas Pertaining to a Pure Phenomenology and to a Phenomenological Philosophy, Third Book (Ideas III). (T. E. Klein \& W. E. Pohl, Trans.). The Hague: Martinus Nijhoff. (Original work published 1952.)

Husserl, E. (1989). Ideas Pertaining to a Pure Phenomenology and to a Phenomenological Philosophy, Second Book (Ideas II). (R. Rojcewicz \& A. Schuwer, Trans.). Dordrecht: Kluwer Academic Publishers. (Original work published 1962.)

Husserl, E. (2001). Analyses Concerning Passive and Active Synthesis. (A. J. Steinbock, Trans.). Dordrecht: Kluwer Academic Publishers. (Original work published 1966.)

Luria, A. (1966). Human Brain and Psychological Processes. (B. Haigh, Trans.). New York: Harper \& Row. (Original work published 1963.)

Luria, A. (1973). The Working Brain: An Introduction to Neuropsychology. (B. Haigh, Trans.). Harmondsworth, England: Penguin Books. (Original work published same year: 1973.)

Merleau-Ponty, M. (1962). Phenomenology of Perception. (C. Smith, Trans.). London: Routledge \& Kegan Paul. (Original work published 1945.)

Merleau-Ponty, M. (1968). The Visible and the Invisible. C. Lefort (Ed.). (A. Lingis, Trans.). Evanston, IL: Northwestern University Press. (Original work published 1964.)

Merleau-Ponty, M. (1988). In Praise of Philosophy. (J Wild \& J. Edie, Trans.). Evanston, IL: Northwestern University Press. (Original work published in 1953 by Librairie Gallimard, Paris.)

Sheets-Johnstone, M. (1990). The Roots of Thinking. Philadelphia: Temple University Press. 
Sheets-Johnstone, M. (1994). The Roots of Power: Animate Form and Gendered Bodies. Chicago: Open Court Publishing.

Sheets-Johnstone, M. (1999/exp. $2^{\text {nd }}$ ed. 2011). The Primacy of Movement. Amsterdam/Philadelphia: John Benjamins Publishing.

Sheets-Johnstone, M. (1999/2009). Emotions and Movement: A Beginning EmpiricalPhenomenological Analysis of Their Relationship. Journal of Consciousness Studies 6, No. 11-12: 259-277; included as Chapter VIII in Sheets-Johnstone, M. (2009). The Corporeal Turn: An Interdisciplinary Reader. Exeter, UK: Imprint Academic.

Sheets-Johnstone, M. (2002). Descriptive Foundations. Interdisciplinary Studies in Literature and Environment 9 (1),165-179.

Sheets-Johnstone, M. (2005). What Are We Naming? In De Preester, H. \& Knockaert, V. (Eds.), Body Image and Body Schema (pp. 211-231). Amsterdam: John Benjamins Publishing. (Originally presented as Keynote Address at "Body Image and Body Schema Conference," Ghent University, March-April 2003.)

Sheets-Johnstone, M. (2008). The Roots of Morality. University Park, PA: Pennsylvania State University Press.

Sheets-Johnstone, M. (2009). Animation: The Fundamental, Essential, and Properly Descriptive Concept. Continental Philosophy Review (42). 375-400.

Sheets-Johnstone, M. (2014a). On the Origin, Nature, and Genesis of Habit. Phenomenology and Mind (6). 76-89.

Sheets-Johnstone, M. (2014b). Animation: Analyses, Elaborations, and Implications, Husserl Studies, 30(3), 247-268.

Sheets-Johnstone, M. (Forthcoming 2017). In Stanghellini, G., Broome, M., Fernandez, A., Fusar-Poli, P., Raballo,1 A., \& Rosfort, R. (Eds.), Merleau-Ponty, Phenomenology, and Psychopathology. Oxford: Oxford University Press. 